\title{
A Japan compact bus terminal; Review on Hakata bus terminal, Fukuoka
}

\author{
Khosyiatillah Hakim $^{\mathrm{a}^{*}}$, Bart Julien Dewancker ${ }^{\mathrm{b}}$, Usep Surahman ${ }^{\mathrm{a}}$ \\ ${ }^{a}$ Universitas Pendidikan Indonesia, Setiabudi, Bandung 40154, Indonesia \\ ${ }^{b}$ University of Kitakyushu, Hibikino 1-1, Kitakyushu, Japan \\ *Corresponding author. Tel.: +62-857-221-99488. \\ E-mail address: khosyiatillah.hakim@upi.student.edu
}

\begin{abstract}
A mass transportation system has a main role in every development process of countries in the modern world. In Japan, transportation infrastructure such as train stations or bus terminals plays as an important node that determines the development of functions and other community activities in the surrounding area. Based on the compact city development concept, various types of transport infrastructure were constructed in the integrated area of city nodes and mixed with a various public and commercial functions and supported with a well-structured management of transportation systems. With the condition of limited land in the city nodes, transport infrastructure has to be built as a compact building. This paper reviews design and system of Bus Terminal in Japan from the architectural perspective with the issue of a compact building. As a study case, Hakata Bus terminal is one of Japanese bus terminal built with a slim building and vertically extended level without bus parking area. The platform was divided into three different floor levels with total ten building stories filled by various public and commercial functions. Time schedule, information system, people and vehicle circulation, and the other aspect become the main support to create a compact bus terminal. However, the commercial function is more prominent than the overall function of the building, thus making Hakata bus terminal does not show the typology terminal design in general. Overall, the terminal provides community services without ignoring the main function as a mass transportation system in a compact bus terminal.
\end{abstract}

Keywords: compact bus terminal; transportation system; Japan

\section{Introduction}

\subsection{Japan transportation and nodes}

Based on Ministry of Land, Infrastructure, and Tourism (MLIT) Japan, from 1980 until 2000 Japan urban development is concentrated around several key urban nodes inside the city. This period has created several important nodes of community activities in several areas of the city in Japan. The placement of transportation infrastructure have a big role in this development to become a core of the development nodes and affect the surrounding area and linked with public's activity needs such as public space, public facilities, education, hospital, commercial area, residential, and other function.

After 2000 until the present, Japan urban development is based on Environmentally-Oriented Urban Development (Compact City). This concept was applied to face problems in the future development of the coming of depopulation and hyper-aged society, the necessity to reduce environmental load, and increase in competition between global Cities. Live in a community centered around core urban functions and public services. While realizing a good urban space efficiently, secure sustainability, safety, and security. 


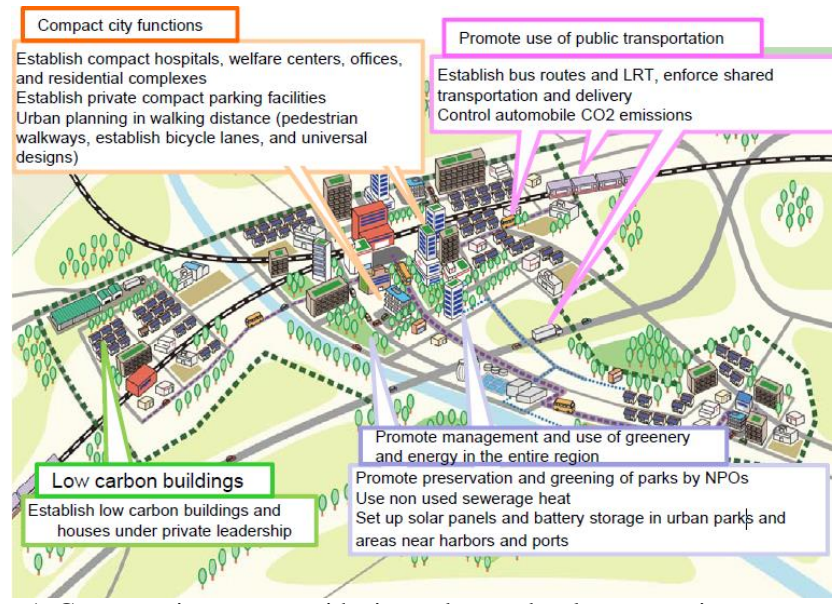

Fig. 1. Compact city concept with city node as a development point (MLIT, 2016).

Environmentally Oriented Urban Development is a concept which expecting a sustainable compact city by promoting a strategy of concentrating urban development on key transportation nodes and by improving the convenience of using public transportation (MLIT Japan, 2016). Also the theory of Transit Oriented Development plan to maximize access to public transport with centrally located rail or bus stations surrounded by relatively highdensity commercial and residential development. Every city nodes was designed with urban planning in walking distance (pedestrian walkways, establish bicycle lanes, and universal designs) and support by promote the use of public transportation. The main node in the city called by City Center Zone or City Square that placed with a main transportation hubs linked with other areas in the metropolis via public transportation networks (Compact City + network). This concept already applied in some city of Japan such as Toyama City, Aomori City, or some city center area in Japan.

Although the train is the main public transportation in Japan, but bus as the other public transportation is also important to be an alternative option and also be able to reach areas that unreachable by train. Rather than put it away from the density of the city, bus terminal in Japan is usually placed integrated with the train station in the city node. With supported by a well-organized time management of Japan transportation and also problem of compact and limited area of public infrastructure in the center of city, bus terminal in japan as transport infrastructure has to be built with a design of compact building and system.

\subsection{Case Study Background}

Based on comparison with a bus terminal design in the overall terminal in the world, Hakata Bus terminal have an interesting point from the architectural design and system. Usually, the bus terminal design was wide extended horizontally, with a number of the platform, a large bus park area, and the terminal function has a strong identity in building typology as a terminal than the other supporting function. In Japan, bus terminal does not show the typology terminal design in general, bus terminal in japan usually just a number of a platform for take and drop the passenger or obscured by other supporting functions. Then for Hakata Bus Terminal case, the building was slim and extended vertically, with no bus park area, and the bus platform separated into 3 different floor. The bus terminal area only takes around $20 \%$ from the total building area, and the $80 \%$ other is filled more by public and commercial function. With that reason, this paper will focus on the compact issues of Hakata Bus Terminal building design. When we talk about a compact building, we can learn how to design a building with a complex and mixed function could be built with consider the eficiency in space and reduce the unnececarry space used.

\subsection{Research methods}

The purpose of this research is to understanding the design and the system of Bus Terminal in Japan from architectural field view. By using the method of Analysis Descriptive, this paper tries to breakdown the whole collected data and revise it from the compact building design in architectural field view. 


\section{Japan Bus Terminal}

\subsection{Overall Japan Bus Terminal Type}

Based on the concept of compact city and supported with well-time management and well-organized transportation, design typologies of bus terminal in Japan tend to be compact and buildable in a limited land. Development of the bus terminal in every node of the city sub-center services is purposed for urban development oriented at public's gather points and public movement distributor (transit oriented development - TOD). Bus terminals that built to support a node will be placed in an area that integrated with other transport (train, subway, etc). Even in some cases, bus terminal only formed by a number of the platform for take and drop the passenger. The determine of public's nodes in Japan depending or affect by the location of the points of the train or subway main station, or so-called station square. Then development of other transport systems such as buses, light rail, around the station is intended to support the public movement around the city center area. The location of the bus terminal would normally support a city center zone node, while a bus stop in another area just a platform take and drop the passenger.

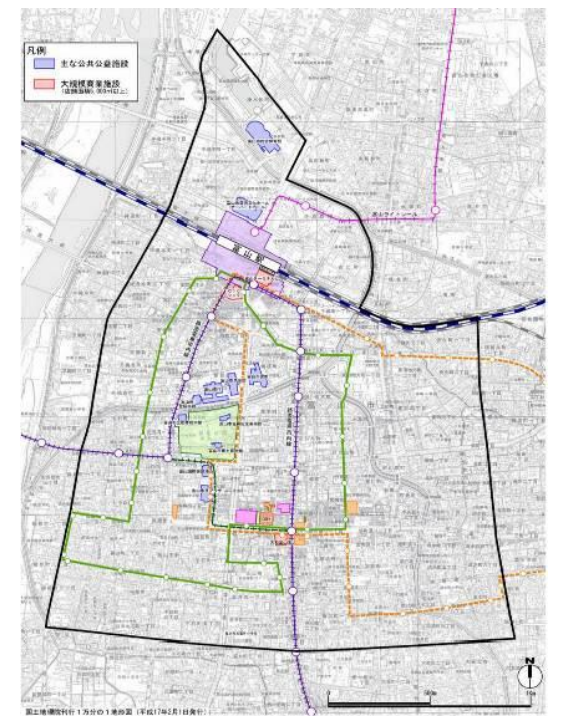

Fig. 2 Map of public transport routes inner the city center zone of compact city Toyama, Japan (MLIT, 2016).

The division of terminal typology in Japan is different with the typology bus terminal in general. Usually, typology bus terminal is divided based service coverage. And this typology which usually determines the terminal design standards from the area, function, to the management system in it. But in Japan, the typology of the bus terminal is only divided by management, those are general bus terminal and private bus terminal.

The general bus terminal is a bus terminal which has a variety of bus companies that provide transportation services. There is more than one bus company that provides the service for the passenger. From Ministry of land, Infrastructure, and Transportation on April 2015, the amount of general bus terminal all over japan is 24 terminal. And the rest is private terminal.

Private bus terminal is a bus terminal that is specific to a particular bus company. The business management and the services for transportation facilities that provided by the terminal running only by one bus company.

After collecting some data and analysis on literature and field survey to several bus terminal in Japan, here is some bus terminal in Japan that have a different categories in building form:

1. Some bus terminal not count as a bus terminal because it's only in a form of platform for take and drop a passenger that integrated with a train station. The picture below is the example, Kokura Bus Center, Kitakyushu, that integrated and merged with Kokura Station building. 
a)

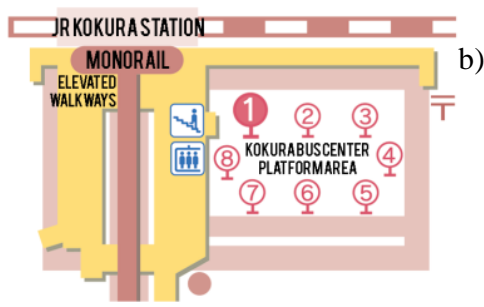

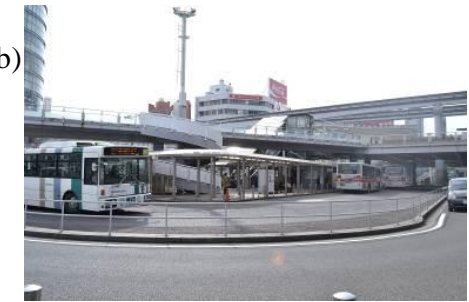

m (b) of Kokura Bus Center.

2. A General bus terminal that located around City center node which has it's own building and management for the bus system. The picture above is the example, there are Osaka City Air terminal, Shinjuku Busta \& Hakata Bus Terminal. This three bus terminal have it's own building and also integrated with the train station and other public transportation

a)

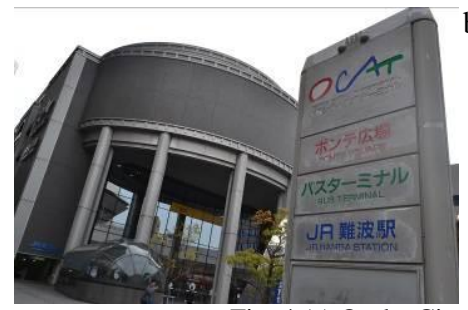

b)

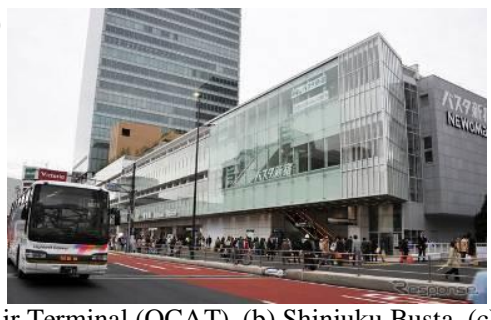

c)

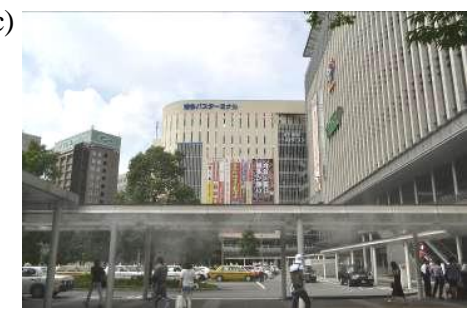

Fig. 4 (a) Osaka City Air Terminal (OCAT), (b) Shinjuku Busta, (c) Hakata Bus Terminal.

3. A bus terminal which becomes a part of a building. The picture above is Nishitetsu Kurosaki bus terminal, a private bus terminal which located on the first floor of Com City building. Com city located in the center node of Yahatanishi ward, Kitakyushu that linked with Kurosaki train station.
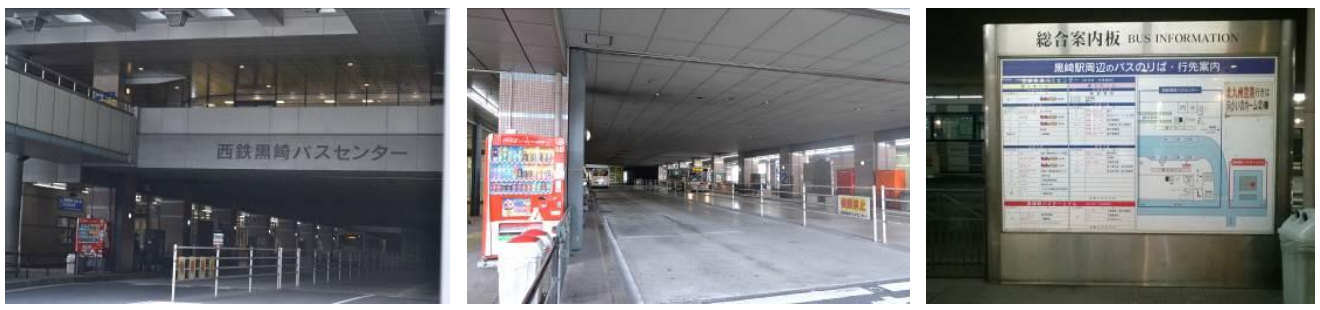

Fig. 5 Nishitetsu Kurosaki Bus Center.

4. A private bus terminal which has a simple bus platform and has a function as the last stops and the starting point of some bus company or usually called bus pool. This kind of bus terminal has a parking area/bus pool, the test vehicle, garage and other bus supporting functions needed. The picture above is Sunatsu Bus Center which owned by Nishitetsu bus company. This terminal located not really close to some city node and not integrated with another public transportation, but become the start and end point for Nishitetsu bus around Kitakyushu city area.

a)

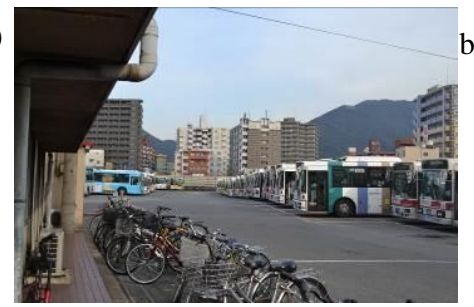

b)

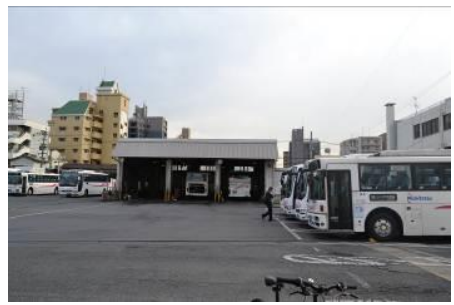

c)

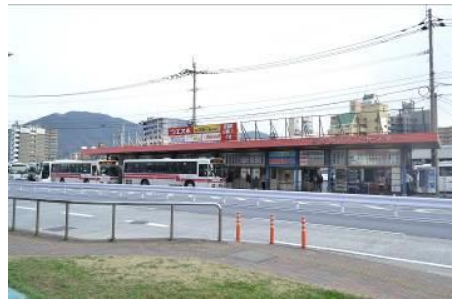

Fig. 6 bus park/pool (a), bus garage(b), and platform(c) of Sunatsu Bus Center. 


\subsection{Case Study : Hakata Bus Terminal}

Hakata Bus Terminal is a general bus terminal that located in Fukuoka city center zone, Japan. Hakata Bus terminal have a function to provide city center node needs of transportation beside the train, subway, taxi, and the other public transportation. Hakata Bus Terminal is integrated with another public transportation inside the Fukuoka traffic center zone. Hakata Station Zone is an important zone for the development of surrounding area because it provides transportation service inside and also to the outer Fukuoka city main node and become a welcome point for Fukuoka city. Fukuoka city center zone consist main public transportation infrastructure of Fukuoka city, but also several public, commercial, and tourism function such as post office, bank, plaza of hakata station, Canal City shopping mall, Kushida Shrine, etc. Hakata Bus Terminal provide an intercity bus service for support the public transportation needs around fukuoka city area which didn't reached by train or subway routes. And also provide an interstate routes bus and tourist/chartered bus as an option of public transportation beside train, plane, or ship.

a)

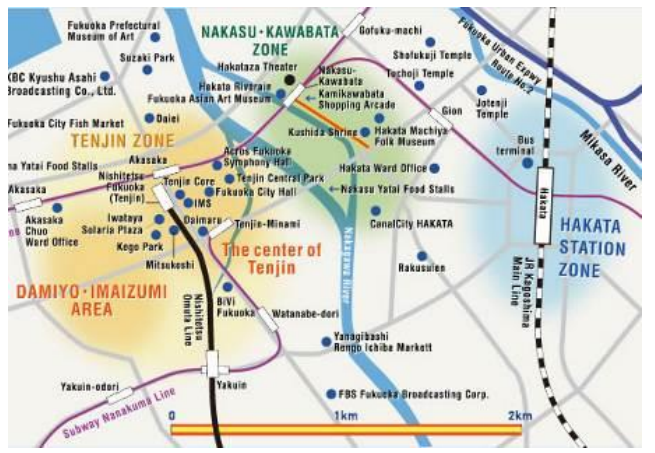

b)

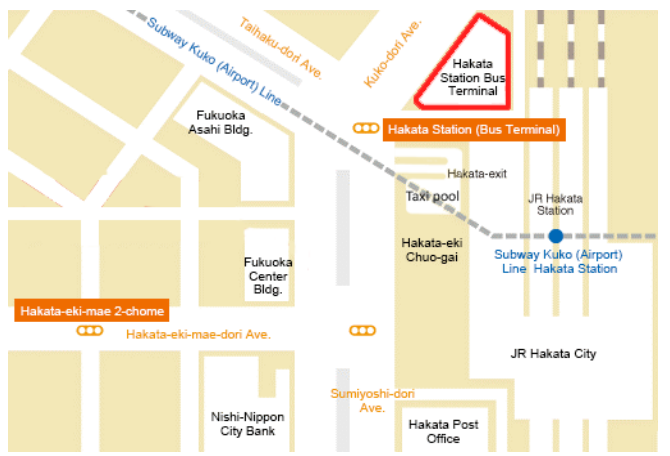

Fig. 7 (a) Fukuoka city center zone (b) Fukuoka traffic center zone.

2.2.1. Building Information:

- Name

- Location

- Completion date

- Owner

- Total area

- Floor

- Type

- Route service

- Arrival and departures

- Occupancy

- Number of employees
: Hakata Bus Terminal

: Hakata-ku, Fukuoka City Hakataeki Chuogai No. 2 No. 1, Japan

: 2015 December 20 (Sunday)

: Ltd. Fukuoka Traffic Center

: 45,634 $\mathrm{m}^{2}$ (bus terminal area : 8,991 $\mathrm{m}^{2}$ )

: Total 10 floor (bus terminal : 3 floor)

: General bus terminal

: intercity bus, tour bus/chartered bus, airport bus and highway bus

: about 3,120 flights / day

: 70,000 people / day

: 33 people

\subsubsection{Connection with surrounding area}

Hakata bus terminal located inside the Traffic Center Fukuoka area which is connected by public transport train, subway, and taxis and regarded as the gateway of Fukuoka. Hakata Bus terminal itself can be accessed from 3 different level entrance. The basement floor or "Bus Chika floor" was connect directly to subway facilities area. The first floor of a building can be accessed from surrounding area which is on the ground level. The entrance was provided with a zebra cross and traffic light to organize the movement of people and bus. And the $2^{\text {nd }}$ floor can be accessed from bridge corridor. This bridge corridor connects the $2^{\text {nd }}$ floor of Hakata Station and also connect the surrounding area from ground level by escalator and elevator. The bridge corridor has a function to reduce the intersection between people and vehicles to make the bus vehicle lane can move more smoothly. 
a)

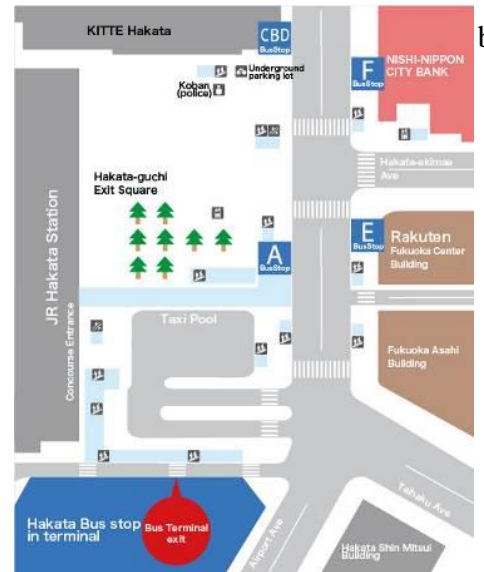

b)

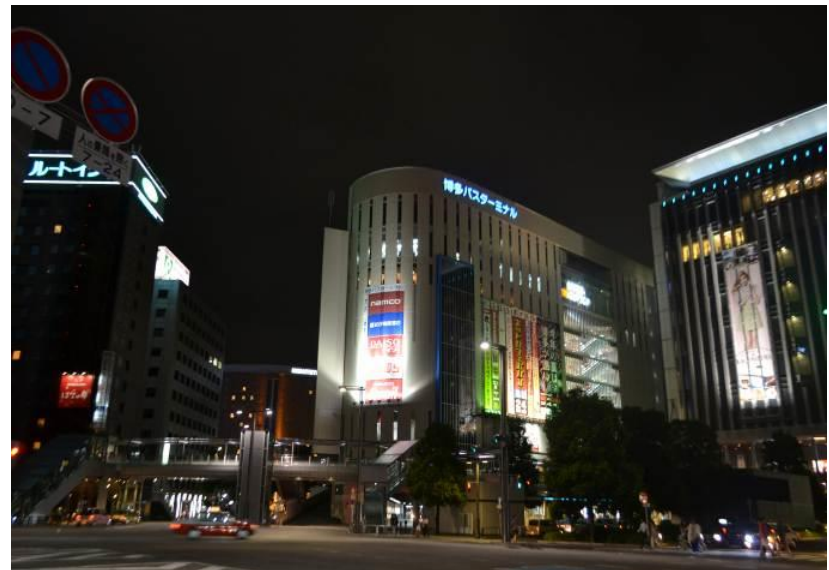

Fig. 8 (a) Hakata Bus Terminal surrounding area, (b) Hakata Bus Terminal view from across the street.

Hakata Bus Terminal does not provide car parking facilities, so that passengers who come to the site come mainly using public transport. As for visitors who use private cars can only be parked in the parking building commercial area is around the bus terminal. Taxi parking area is also available to support the needs of the entire area Fukuoka traffic center is not just a bus terminal.

a)

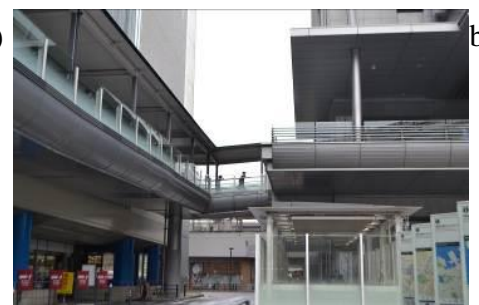

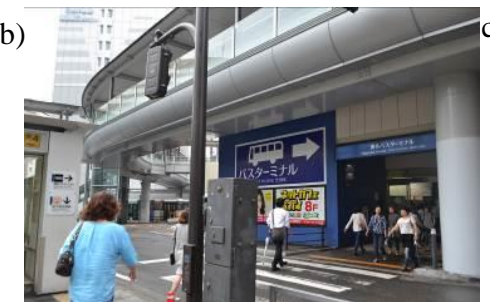

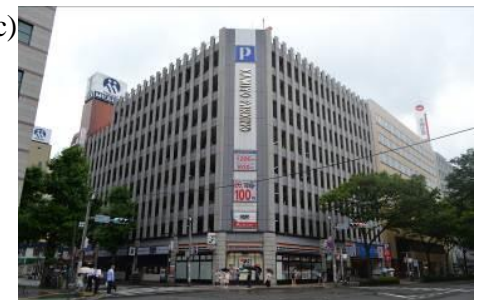

Fig. 9 (a) connection bridge with Hakata Station, (b) zebra cross to entrance gate, (c) parking building near Hakata area.

\subsubsection{Space Function:}

Hakata bus terminal is a bus terminal that built vertically in a building. Bus terminal function was separated in 3 floors of building from $1^{\text {st }}$ floor to $3^{\text {rd }}$ floor. And the commercial function shopping mall $\&$ rental space was spread from basement 1 to $9^{\text {th }}$ floor. Hakata bus terminal was divided into 2 functions which is called "Basu-noriba" or means bus terminal area for take and drop the bus passenger and "Senmontengai" or means a shopping mall area for commercial space.

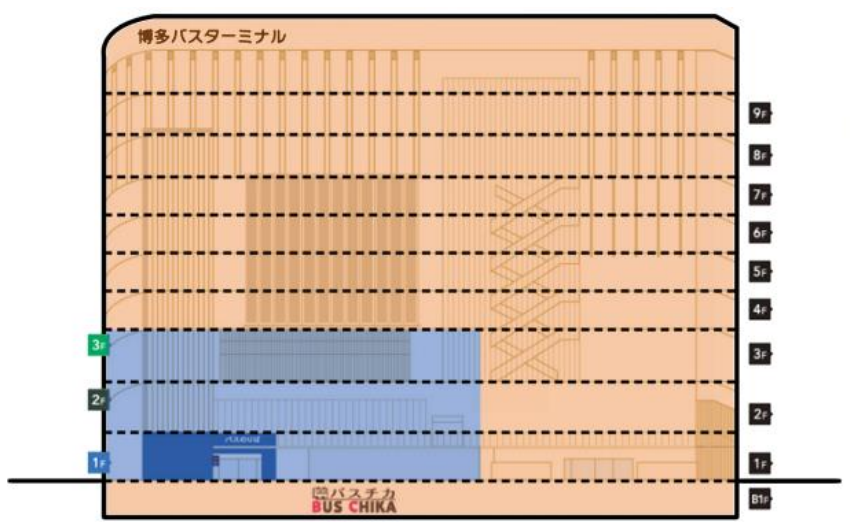

Fig. 10 Zoning building function of Hakata Bus Terminal.
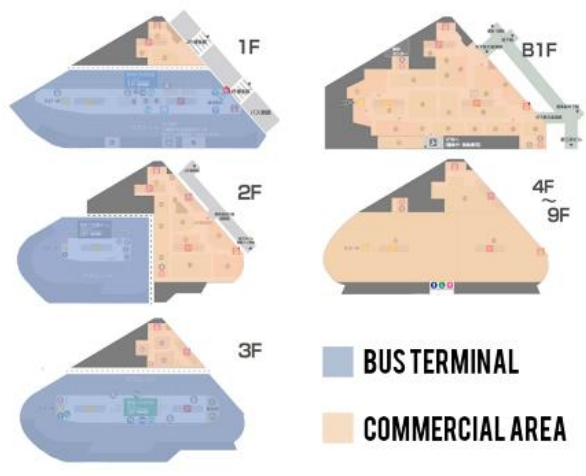

BUS TERMINAL

COMMERCIALAREA 
1.) Basu Noriba (Bus Terminal Area)

three-storey bus terminal area consists of:

- 3rd floor : : high-speed bus stop, JR Kyushu Bus Stop

- 2nd floor : : high-speed bus drop-off area, Nishitetsu bus, Showa automobiles, and chartered bus stop

- 1 st floor : Nishitetsu Bus (intercity bus) stop

Bus terminal main facilities: departure platform, arrival platform, waiting area (seating), ticketing facilities, information and signage, vehicle circulation, people circulation (hallways, elevator, escalator, etc), Security and management office.

Bus terminal supporting facilities: Toilet, rental space, baggage lockers, public telephones, nursery room, smoking area, and handicap facilities.

2.) Commercial \& Public Function

Commercial space was various from a restaurant, shop for foods and sweets, mobile phone shop, fashion and accessories shop, relaxation and beauty shop100 yen shop, office rental space, rental hall, game center, souvenir shop, service, and other.

\section{Analysis and Discussion}

Compact is an adjective word which has a meaning of closely and neatly packed together; dense. Or in the other meaning is having all the necessary components or features neatly fitted into a small space. With based on the compact building aspect, Hakata Bus Terminal reviewed with focusing on efficiency in space that can make this public transport infrastructure work maximally in the minimum space. For a bus terminal, some space that can be an aspect point for a compact terminal building is circulation layout of people and vehicles, time management, information systems, and other supporting facilities.

\subsection{Circulation Layout}

Hakata Bus terminal separates the circulation of people and vehicles. Activities modes of vehicles in the bus terminal are private and closed off from visitors. The passenger ride and take off the bus directly from the bus platform door to the indoor area of the terminal. This circulation system avoids conflict between circulation between people and vehicles.
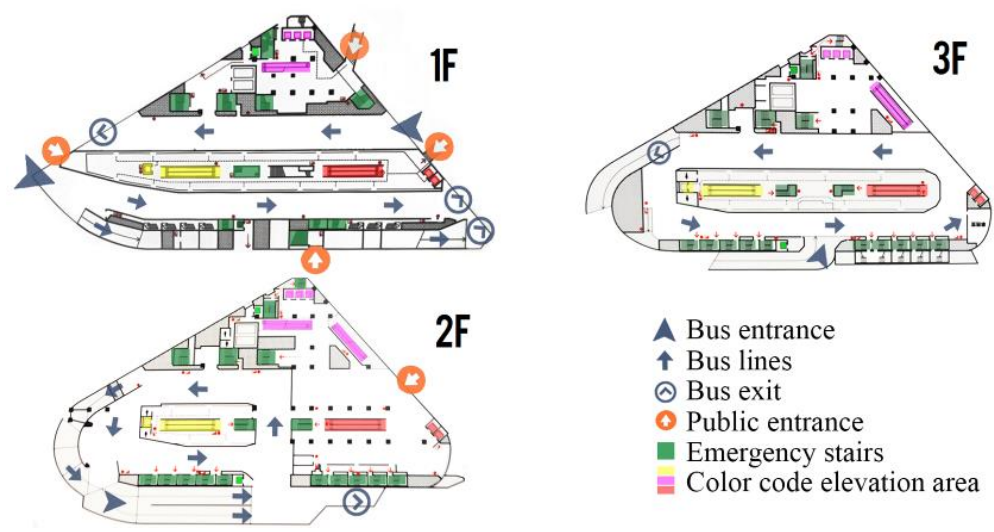

Fig. 11 Circulation Layout of "Basu Noriba" area from 1st floor to 3rd floor.

Hakata bus terminal has a 3 color guide elevation system. The yellow and red color is the elevation that connects to the bus terminal area, and the purple color is the elevation only for the commercial area / shopping mall. Also, emergency route was put in a reachable area. Also, there is other color-coded sign to lead the people circulation without use a barrier make the movement space more flexible. 
a)
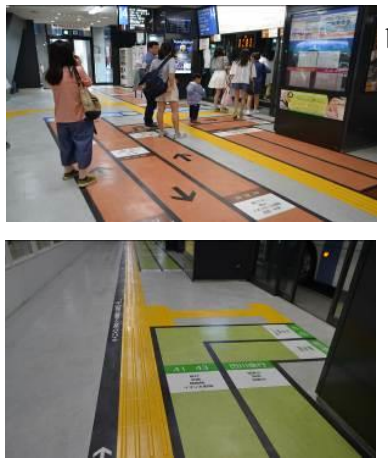

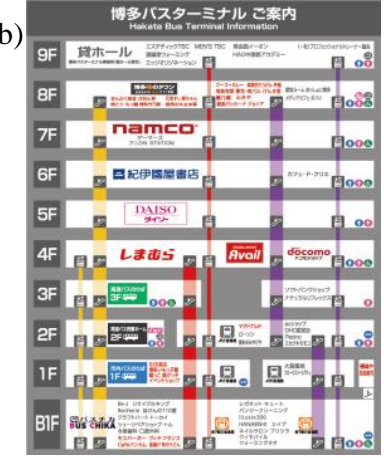

Fig. 12 (a) passenger direction and handicap guiding block, (b) color code elevation.

\subsection{Time Management}

Time management is an important aspect that affects the needs of terminal space. Well-management of time could reduce the accumulation and unnecessary movement of buses inside the terminal. Hakata bus terminal which incidentally is the part of Japanese transportation infrastructure has been supported by the well-management of bus movement time so that the buses only come and left the terminal right according to the schedule.

The length of time that used by the bus at the terminal to pick and drop the passengers is only about 1-2 minutes for intercity buses, about less than 30 minutes for highway bus to take up the passenger, and about 10 minutes for drop the passenger. There will not be a buses queue inside the bus terminal because the whole bus arrival schedule is already organized in order to avoid the bus accumulation.

a)
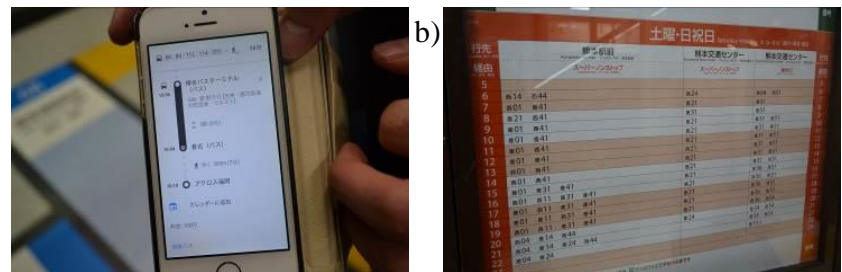

Fig. 13 (a) route and schedule information on the internet (b) timetable of bus.

\subsection{Information System \& Signage}

Wayfinding system help people to orient themselves and let people decide by themsleves when and where they will to go. With provide a clear wayfinding system, the building will reduse the effort to organized the movement of people inside the building. Wayfinding system inside a bus terminal can be the form of Information and signage for the passenger that provided about all the bus operation of the terminal.

In Hakata Bus Terminal, wayfinding system shows the whole information bus terminal operation and lead the passenger to act by themselves such as information route, travel guides, route map, timetable, each platform detail information, and the other information signs. Also color coded signage such as that used on elevation, platform type, direction, and other color-coded sign makes passenger understand easier about every facilities inside the terminal. Also for the foreigner visitor, Hakata bus terminal provide a multi-language information on information board/screen, pamphlet, and also on the website.
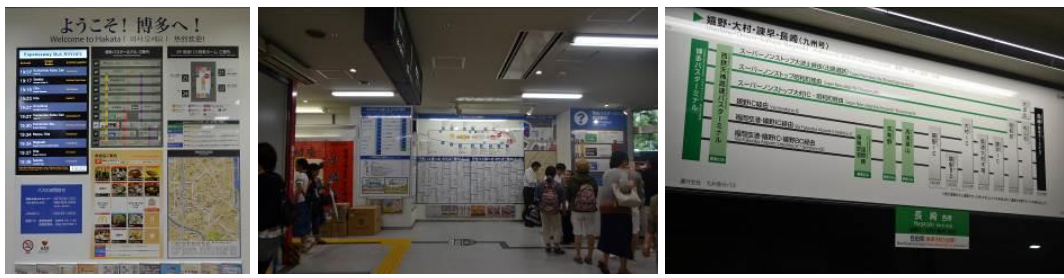

Fig. 14 Information on the wall and platform. 


\subsection{Other Facilities}

\subsubsection{Seating}

The amount of public seating varies depending on individual circumstances, terminal type, and economic priorities. From As a general rule, an allowance of one seat for every three passengers would be adequate for an intercity terminal. From the average bus capacity (35-37 people) means every platform is needed around 11 seats (De Chiara \& Callender, 1987). When compared with the general standard, Hakata bus terminal is far from the criteria. On the intercity bus area on $1^{\text {st }}$ floor of Hakata Bus Terminal only provide 12 seats for 14 bus platform, for the $2^{\text {nd }}$ floor highway bus arrival area, they have 6 seats for 4 platforms, and for the $3^{\text {rd }}$ floor highway bus area, they have 125 seats for 8 platforms.

The minimum provision of a seating facility is still correlated with the function of a compact bus terminal that close to other commercial function lead the passengers chose to spend the waiting time in the area outside the bus terminal. Thus reducing the crowd amount of passengers inside the terminal area.

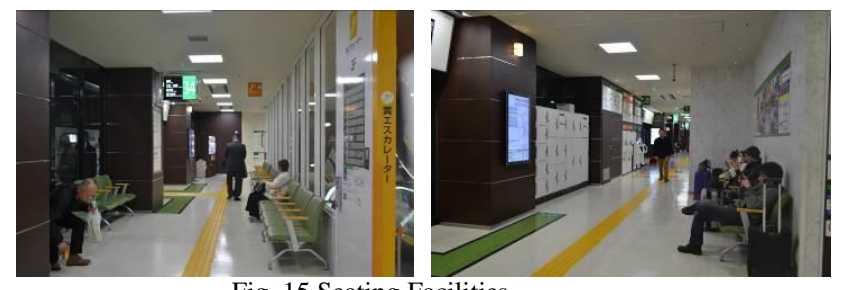

Fig. 15 Seating Facilities.

\subsubsection{Ticketing system}

For city bus, the passenger didn't have to buy any ticket for the ride a bus but they pay directly when after using the bus service inside the bus. For the highway ticket, the ticket can be bought by online, convenient store, and a ticket machine that provides inside the bus terminal. Or they can buy the ticket directly at Hakata bus terminal $3^{\text {rd }}$ floor. This system letting people not have to line up for buying ticket at terminal

a)
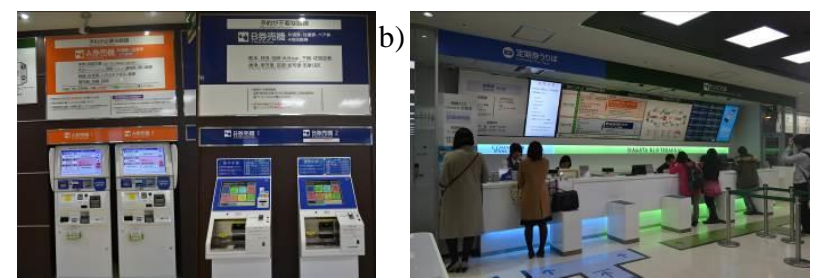

Fig. 16 (a) Ticket machine, (b) Ticket counter.

\subsection{3. kiosk/rental space}

Rental space inside the bus terminal area was a rented space for a small simple kiosk that sells a takeaway products for the bus passenger. They selling things like a takeaway food, or some goods or souvenir. The kind of product that sell in this kiosk was a product that didn't need to keep the consumer take a lot of time to buy something from that shop. This shop avoids the accumulation of people circulation inside the terminal.

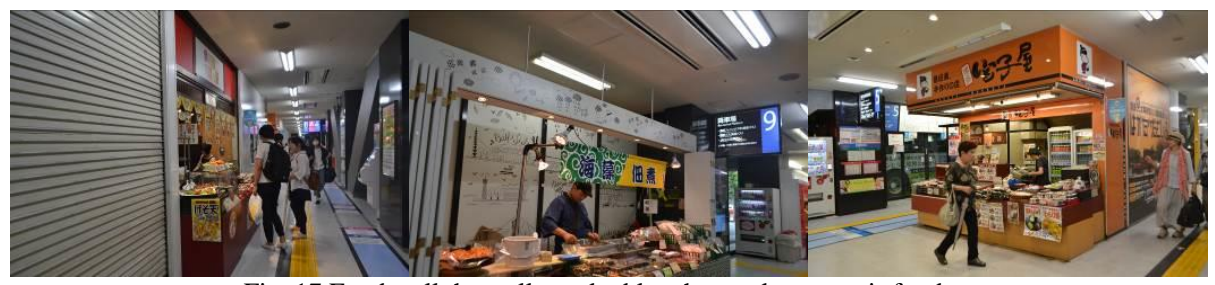

Fig. 17 Food stall that sells packed lunch, snack, souvenir food, etc. 


\subsection{4. baggage lockers}

Baggage lockers facilities provided for the bus passenger that want to look around while their wait for the bus or when they arrive and look around before it's time for them to leave Hakata area. This facilities was provided more on the highway platform area.

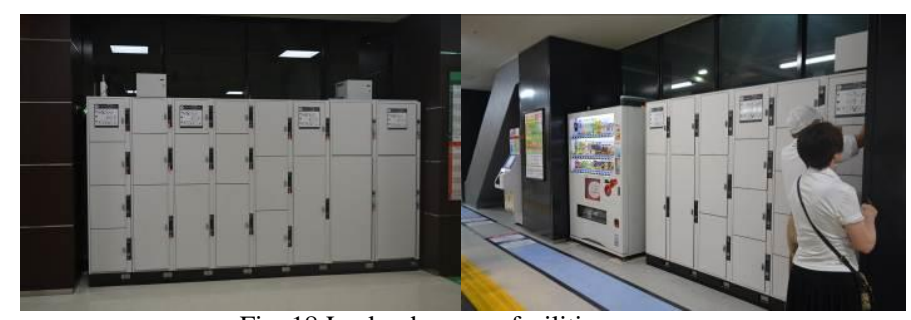

Fig. 18 Locker baggage facilities.

\section{Conclusion}

Japan development concept began to lead to the development to a compact urban development where various functions placed adjacent to each other and support each other with a support from the important role of public transportation. Main bus terminal placed in city center area to support the needs of public transport which not reached by the train line. The integrated transport system and linked to another public function inside the center zone area indirectly require the development of design and system of a bus terminal work efficiently and compact of building function even on the limited land area.

This paper look more closely to Hakata Bus Terminal as a study case of Japan Compact Bus Terminal to analyze some building aspect that support a bus terminal as a public transport infrastructure that can be built in a minimum space but still work maximally and also still consider the needs of the passenger. With a clear separation in circulation layout of people and vehicles, well organized time management and schedule, maximal information and signage for wayfinding systems, and also provide some other supporting facilities, Hakata Bus Terminal can work eficiency in the limited area and inside the compact building. Despite the limited land and not show a general typology of the bus terminal, but Hakata bus terminal has a system, design, and facilities that capable of providing adequate service as public transport infrastructure.

\section{Future Research}

This far, Hakata Bus Terminal only analyzed by viewable point as a visitor or investigator and supported by collected literature data. So there's not enough data to complete understanding in compact building aspect on Hakata Bus Terminal. Future research needs to be more detail to look at the whole point until the unseen information data that affect the compact aspect of Hakata bus terminal. Also, need some measurement data that support in scientific ways to prove the effectiveness of the application of the concept of a compact building for the bus terminal design.

\section{References}

De Chiara, J., \& Callender, J. H. (1987). Time-saver standards for building types. Singapore: McGraw-Hill.

MLIT Japan. (2016). Promotion of Urban Renovation and Compact Cities. Retrieved from https://www.mlit.go.jp/common/000996976.pdf 